lostowne

\title{
O protagonismo midiático da multidão nos movimentos sociais
}

\author{
The mediatic leading role of crowds \\ in social movements \\ El protagonismo mediático de la muchedumbre \\ en los movimientos sociales
}

\section{Eduardo Cintra Torres*}

\begin{abstract}
Resumo: A importância adquirida por movimentos sociais e pela sua expressão multitudinária e midiática na vida política e social de países como o Egito, a Tunísia, o Brasil, a Turquia ou a Ucrânia é aceita com unanimidade pelos analistas na imprensa e nos estudos acadêmicos. Este artigo pretende refletir sobre aspectos que, todavia, não parecem estar devidamente identificados e estabelecidos: o momento de multidão como, ainda e sempre, o ponto de viragem no impacto de um movimento social; a relevância da multidão para além do eventual fracasso dos objetivos que a motivaram; a explicação da manutenção da importância das midias "tradicionais" na era da Internet e das redes sociais eletrônicas; a filiação histórica das principais características do fenômeno multitudinário e o acento correto no que é realmente novo, caso do marcado empoderamento do indivíduo em algumas multidões contemporâneas, como as do Brasil em 2013, e a fluidez do ativismo nas democracias desenvolvidas.
\end{abstract}

Palavras-chave: movimentos sociais; multidão; sociologia das mídias; redes sociais electrônicas

Abstract: The importance acquired by social movements and their multitudinous and media expressions in political and social life of countries like Egypt, Tunisia, Brazil, Turkey or Ukraine is accepted unanimously by the analysts in the press and academic studies. This article aims to reflect on aspects which, however, do not seem to be properly identified and established: the crowd event as, still and always, the turning point in the impact of a social movement; the relevance of the crowd beyond the possible failure of the objectives that motivated it; the explanation of the maintenance of the importance of 'traditional' media in the era of the Internet and electronic social

\footnotetext{
*Professor Auxiliar Convidado da Universidade Católica Portuguesa (UCP).<eduardocintratorres@, gmail.com $><$ dados biográficos/biographic data $>$
} 
networks; the historical affiliation of the main features of the multitudinous phenomenon and the correct accent in what is really new, as is the case of the marked individual empowerment in some contemporary crowds, such as Brazil in 2013, and the fluidity of activism in developed democracies.

Keywords: social movements; crowd; media sociology; digital social networks

Resumen: La importancia adquirida por los movimientos sociales y por su expresión multitudinaria y mediática en la vida política y social de países como Egipto, Tunisia, Brasil, Turquía o Ucrania es aceptada por unanimidad por los analistas en la prensa y estudios académicos. Este artículo tiene como objetivo reflexionar sobre aspectos que, sin embargo, no parecen estar debidamente identificados y establecidos: el momento de la muchedumbre como, todavía y siempre, el punto de inflexión en el impacto de un movimiento social; la relevancia de la muchedumbre más allá del posible fracaso de los objetivos que la motivaron; la explicación del mantenimiento de la importancia de los medios de comunicación "tradicionales" en la era de Internet y las redes sociales electrónicas; la afiliación histórica de las principales características del fenómeno multitudinario y el acento correcto en lo que es realmente nuevo, como es el caso del marcado empoderamiento del individuo en algunos muchedumbres contemporáneas, como en Brasil en 2013, y la fluidez del activismo en las democracias desarrolladas.

Palabras clave: movimientos sociales; muchedumbre; sociología de los medios; redes sociales digitales

\section{Introdução}

Como qualquer teoria nas ciências sociais, a da multidão foi fortemente marcada pelo Zeitgeist em que os autores sobre ela refletiram. No final do século XIX e início do século XX, sem realizarem trabalho empírico e marcados pela sua origem de classe burguesa, a maioria dos autores viu de longe a multidão como um fenômeno desligado das suas causas e movimentos e foi incapaz de entender a racionalidade dos indivíduos nas ações multitudinárias, quanto mais a racionalidade social dessas ações ${ }^{1}$. A sociologia norte-americana da primeira metade do século XX procedeu à inserção da multidão na "norma emergente", contribuindo decisivamente para a normalização do fenômeno multitudinário no fluxo da ação social, sem, todavia, se libertar ainda da "irracionalidade" dos indivíduos ou coletivos e operando uma omissão do papel da multidão na vida coletiva que se exprimiu na própria exclusão da palavra nos seus textos. Esta atitude analítica caracterizou não só a sociologia norte-americana como a britânica, estando ainda hoje muito

\footnotetext{
${ }^{1}$ Sobre a teoria da multidão, ver MCCLELLAND (1989), TORRES (2013a) e BORCH (2013). Poucos autores do final do século XIX ou início do seguinte escaparam a esta tendência analítica, destacando-se as últimas obras de TARDE (1992) e de Émile Durkheim (TORRES, 2014) e COOLEY (1909).
} 
presente, apesar da significativa alteração a partir dos movimentos nos EUA pelos direitos civis e contra a guerra no Vietnã.

A teoria da "norma emergente" como que anunciava a nova área de estudo dos movimentos sociais, que se afirmará a partir dos anos 70 (DELLA PORTA; DIANI, 2011; FILLIEULE; PÉCHU, 2014; FILLIEULE; MATHIEU; PÉCHU, 2009; FILLIEULE; AGRIKOLIANSKY; SOMMIER, 2010; NEVEU, 2011). Esta área de estudo incorpora a multidão da manifestação de rua disciplinada no 'repertório' de ações dos movimentos sociais, teorizado e tipificado por Charles Tilly, considerando-a um dos "elementos cruciais" que "separaram o movimento social de outras formas da política" (TILLY, 2009 , p. 3). A manifestação de rua enquanto expressão da "política litigiosa" tornou-se, por imposição da sua crescente presença no espaço público, objeto de estudo em si (TILLY; TARROW, 2007; FILLILEULE; TARTAKOWSKY, 2008; MATHIEU, 2011). A afirmação dos movimentos sociais, incluindo os que adquiriram expressão internacional ou global, contribuiu, entretanto, para a "crise da representação" dos sistemas democráticos, acentuando as formas de expressão e ação da "contrademocracia", isto é, os meios à disposição dos cidadãos para criticarem, controlarem e eventualmente contrariarem as instâncias do poder (SOMMIER, 2003; BOUGNOUX, 2006; ROSANVALLON, 2006). A crescente desinstitucionalização das estruturas da sociedade, como, por exemplo, dos partidos políticos (CHIARAMONTE, 2015), também contribui para a crise da representação, real ou sentida.

Nas últimas décadas, em especial já no século XXI, outros temas adquiriram atenção renovada nas ciências sociais, nomeadamente: a questão das redes sociais, com um interesse muito especial devido à capacidade de comunicação proporcionada pelas novas técnicas de comunicação eletrônica; a questão da expressão pública e política das emoções; e a relação dos movimentos sociais com as mídias, "velhas" e "novas" (CASTELLS, 2009; 2013; GOODWIN et al, 2001; CHAMPAGNE, 1990; NEVEU, 2010). São temas que ocorrem nos casos que abordamos.

\section{O caso egípcio}

A ocupação da Praça Tahir durante longos períodos até à queda do Presidente Hosni Mubarak foi um episódio que comprovou a capacidade transformadora da multidão: o regime caiu, não apenas, mas também, e muito, por causa da multidão. $\mathrm{O}$ caso egípcio distingue-se dos que 
a seguir analisamos por ocorrer numa ditadura. A multidão teria de ser expressão obrigatória da oposição clandestina ao regime. Sem o processo democrático, sem efetivas liberdades políticas e de expressão, os opositores aproveitaram a oportunidade para juntar o maior número num lugar simbólico da capital. Pela mesma razão, era obrigatória a invulgar permanência da multidão na Praça Tahir por longo tempo, ou o movimento arriscava-se a morrer sem obter consequências a curto prazo (CASTELLS 2009, p. 53-109; ASWANY, 2011; ELTANTAWY; WEST, 2011; NUNNS; IDLE, 2011).

O papel das mídias eletrônicas neste combate político tem sido corretamente sublinhado, não só para a articulação das ações, para a sua divulgação em canais e redes sociais eletrônicos, mas também para a sua divulgação junto das mídias internacionais, cujo papel foi essencial para acalentar os manifestantes e manter a pressão sobre o poder político. Potenciando a capacidade mobilizadora de opinião e emoções com a divulgação de imagens através dos meios eletrônicos, opositores a Mubarak prepararam-se antecipadamente para essa tarefa política, através de "cursos" de utilização dos smartphones para gravar imagens e enviá-las de imediato, antes de captura pelas forças militares ou policiais (TORRES, 2011).

Se o uso das técnicas eletrônicas foi generalizado e frutuoso, igualmente significativo foi o papel da televisão e das restantes mídias "tradicionais", como reconheceu o próprio internauta criador da primeira página no Facebook que permitiu o desenvolvimento do movimento social: Wael Ghonim atribuiu às centenas de sítios na Internet e aos canais internacionais de TV Al Jazeera e CNN a manutenção da informação sobre a revolução no período em que a repressão mais se abateu sobre os opositores (GHONIM, 2012). Sendo o regime de Mubarak incapaz de reprimir as gravações e emissões ao vivo de canais de TV, a revolta no Egito veio a originar a inversão do célebre motto "The revolution will not be televised" em diversas versões, que se podem resumir num novo motto: "This revolution will be televised" (TORRES, 2011, p. 173-174). Esta realidade contraria a visão expressa por diversos autores - e de diversos movimentos sociais - a respeito das mídias "tradicionais"2. Ou melhor, o caso egípcio contraria o papel habitualmente atribuído e assumido pelas mídias "tradicionais". Na verdade, eles tiveram um papel ímpar de informação e, portanto, de divulgação do movimento

2 Encontram-se boas revisões da literatura sobre este tema em: (FILLIEULE; MATHIEU; PÉCHU, 2009, p. 349-355) e WOUTERS (2013, p. 83-90). 
social simbolizado pela multidão na Praça Tahir. Destacou-se a rede de televisão Al Jazeera, da família no poder no Catar, com emissões diferenciadas em línguas árabe e inglesa.

As mídias "tradicionais" corresponderam, pois, às necessidades de divulgação do movimento antirregime, que necessitava absolutamente de "exportar" - em sentido literal e metafórico - as imagens da oposição e da multidão para os media regionais e mundiais, além das mídias nacionais que o podiam fazer. A televisão e processos "antigos" dos movimentos sociais, como panfletos, permitiram alargar a informação a setores da população sem acesso à comunicação eletrônica digital. Será coincidência que o emotivo apelo de Ghonim na televisão nacional, depois de libertado pela polícia política, ocorresse quatro dias antes da queda de Mubarak? (GHONIM, 2012). Assim, a visibilidade midiática, em especial televisiva, foi determinante para o êxito do movimento egípcio. Ocorreu um caso exemplar de formação da multidão-sinédoque, almejando a representação do povo egípcio, e da multidão-imagem, transformada em conteúdo informativo, multidão apropriada pelas mídias, em especial pela televisão. Deste modo, era fulcral para o movimento a continuidade dessa sinédoque e dessa imagem, pelo que foi necessário manter a Praça Tahir ocupada nos ecrãs do mundo. A Praça Tahir ocupada pela multidão significou a televisão ocupada com a Praça Tahir. Esta, como lugar simbólico, representou no mundo real a metáfora do "poder na rua", no sentido em que a praça assumiu o centro do poder, em substituição do poder político de Mubarak. Ocupada a Praça Tahir pela multidão, ocupada a televisão com a Praça Tahir, o poder de Mubarak ficou desocupado. Em resumo, tratou-se de um caso brilhante da simbiose entre a multidão e a televisão (TORRES, 2013a). As redes eletrônicas potenciaram a multidão e a televisão potenciou a sua vitória.

A evolução da situação política no Egito criou depois um pessimismo na opinião pública e a desvalorização da luta da oposição ${ }^{3}$. Todavia, tratase de uma avaliação que não toma em conta o poder de reverberação da multidão na sociedade. Na verdade, o fenômeno multitudinário, apesar de efêmero por natureza, deixa marcas nos indivíduos e nas sociedades, podendo, quando parte de episódios revolucionários, contribuir para uma mudança perene da atitude da população face às

\footnotetext{
'Maidan, Ukraine... Tahir, Egypt... the squares symbolise failure, not hope. The lessons of Egypt for Ukraine is that defiant crowds may destroy an old regime- - but they seldom build a new one', escreveu Simon Jenkins no Guardian, 26.02.2014.
} 
elites e ao poder ${ }^{4}$. Por outro lado, essa avaliação também não toma em conta que a multidão não visa necessariamente um único fim nem seria o único meio de o atingir. A Praça Tahir reuniu, não uma oposição a Mubarak, mas oposições; e, sendo a multidão por natureza uma ação "desinstitucionalizada" (mesmo quando promovida por instituições, como partidos, sindicatos, etc.), não tem a capacidade de decidir as opções políticas próprias das instituições. Em consequência, podemos dizer que a multidão da Praça Tahir exprimiu inúmeros pontos de vista, quer política, quer emocionalmente, foi revolucionária no sentido em que foi instrumental para a substituição da ordem existente, criou um lastro de atitude política nos indivíduos e na memória coletiva da sociedade e abriu no Egito e naquela região uma relação entre o coletivo multitudinário nas ruas e a televisão ao vivo, semelhante à que se vai afirmando noutras partes do globo.

\section{O caso norte-americano}

Os movimentos sociais nos Estados Unidos na segunda metade do século XX contra a segregação racial e depois contra a guerra no Vietnã alteraram radicalmente a atitude prevalecente no país a respeito da multidão política. $\mathrm{O}$ sistema político norte-americano foi criado de modo a evitar-se revoltas e a sua disseminação. Seguindo a tradição britânica, que se espelha na teoria política e sociológica dos dois países na mudança do século XIX para o século XX, dominou a visão negativa da multidão (crowd), quase sempre confundida com a turba violenta (mob). Tal como na Europa Continental, a posição de classe dos autores perante a multidão nas ruas - maioritariamente das classes populares a quem eram negados direitos políticos e de associação - toldava a possibilidade de uma análise mais científica. A inclusão da multidão no âmbito da criação de uma "norma emergente" na sociedade, através do que viria a chamar-se "movimentos sociais", constitui um passo em frente, mas ao mesmo tempo dissolveu a importância do significado e alcance da realidade multitudinária nas ruas, como o movimento contra a segregação social viria a demonstrar ${ }^{5}$. Não será coincidência que, sem interesse pelo estudo da multidão e com a violência como pano de fundo, mais imaginado do que real, da realidade da rua, as

\footnotetext{
${ }_{4}$ A partir de 1789, "a obsessão revolucionária, quer quando partilhada quer quando denegrida, torna-se uma característica determinante da civilização europeia" (SOLÉ, 2008, p. 14).

5 Turner e Killian $(1987$, p. 3$)$ introduziram o conceito de "norma emergente" na sociologia do comportamento coletivo.
} 
ciências sociais norte-americanas conhecessem um grande impulso do estudo dos movimentos sociais e, também, da "violência coletiva". Seguindo a tática da não-violência de Mahatma Gandhi na luta pela independência da Índia, o movimento dirigido por Martin Luther King foi acutilante na escolha de um repertório de ação que envolvesse as mídias e, através delas, chegasse à "opinião pública", nomeadamente através do despertar de emoções de pena e horror perante as imagens da repressão dos manifestantes (TORRES, 2013a; BORCH, 2013; TILLY, 2006; TILLY; TARROW, 2007; SHARP, 2005). A simpatia das mídias para com o movimento, invulgar na sociedade norte-americana, foi crucial para, pela visibilidade que lhe deu, quebrar o silêncio "insuportável" da "maioria silenciosa" ou inverter a "espiral do silêncio" (BAUDRILLARD, 1982; NOELLE-NEUMANN, 1975). O êxito do movimento foi coroado na Marcha sobre Washington, em 28 de Agosto de 1963, que, transmitida ao vivo pelas redes generalistas, simbolizando a fusão da multidão e da televisão, proporcionou à presidência de John Kennedy tomar a iniciativa (TORRES, 2011; 2013a). Já o movimento contra a guerra do Vietnã, por ser menos consensual na sociedade e no universo político, representou de alguma forma um regresso ao modelo anterior da relação das mídias "tradicionais", tanto mais que os grupos políticos mais periféricos e radicais assumiam nele uma presença de peso. Todavia, teve um inegável êxito na alteração da opinião pública ${ }^{6}$. Em plena era da comunicação e redes sociais eletrônicas, o movimento "Occupy Wall Street" de 2011 veio mostrar os bloqueios que impedem o êxito completo de movimentos sociais contemporâneos (GITLIN, 2012). Dominado por libertários e anarquistas, o Occupy não tinha liderança e porta-vozes oficiais, dificultando a sua expressão pública através das mídias "tradicionais", e rejeitando, aliás, a estratégia de conquista da simpatia dessas mídias. Por outro lado, o modelo anarquista de "multidão horizontal" torna o processo decisório excruciante e a ocupação de espaços públicos por um período demasiado longo contraria a natureza dos coletivos multitudinários e acaba por morrer por si mesma. Assim, as virtualidades e possibilidades fornecidas pela comunicação eletrônica - que seguiu o modelo de gravação e divulgação usado antes no Egito - acabam desperdiçadas se se pretende conquistar a "maioria silenciosa" para a ação ou constranger o poder político a tomar medidas propostas, o que, aliás, nem era objetivo para muitos dos

\footnotetext{
Sobre a estratégia e a tática da "Nova Esquerda" e outros movimentos sociais americanos e a política das mídias neste período, ver: (GITLIN, 2003).
} 
manifestantes. Este movimento serve também de exemplo dos limites das redes sociais eletrônicas: o seu uso em pleno é insuficiente para capacitar qualquer tipo de mudança substantiva ou objetiva na sociedade e não apenas na subjetividade dos indivíduos 7 . Apesar disso, o Occupy contribuiu para a alteração de ideias na sociedade em geral a respeito do capitalismo financeiro, como revelaram sondagens (GITLIN, 2012, p. 37-41). A ação multitudinária morre, mas a realidade resultante é diferente da anterior. Como no fim de Germinal, o romance da multidão por excelência, sobra para os envolvidos a esperança de que fica na terra "o ruído dos germes", comparado ao "rumor" de um "exército negro, vingador, germinando lentamente nos sulcos, crescendo para as colheitas do século futuro" (ZOLA, 1978, p. 594).

\section{O caso brasileiro}

Tal como na Tunísia e no Egito, onde uma imolação e um assassinato desencadearam a expressão visível do movimento social, no Brasil um aumento de preço em transportes públicos originou um movimento multitudinário reunindo diferentes queixas e reivindicações amalgamadas num sentir comum (CARDOSO; DI FATIMA, 2013; VV.AA., 2013). Os aspectos que mais nos interessam aqui realçar do movimento social no Brasil em 2013-14 são, por um lado, essa diversidade de motivos para os protestos e, por outro, a relação entre estes e as mídias.

A multiplicidade das queixas e reivindicações - em alguns casos apenas desabafos - é bem visível nos cartazes individuais levados pelos manifestantes. Se esse traço já se verificava em iniciativas anteriores noutros países, ele está particularmente presente nas manifestações iniciadas em Maio e Junho de 2013 no Brasil. Só para mencionar um caso, citemos dois desabafos de sentido contrário numa mesma manifestação no Recife: um manifestante anunciava "Sou gay", enquanto vinte metros à sua frente um outro desabafava: "Eu gosto de mulher. $\mathrm{E}$ daí?!" A pluralidade de mensagens e, portanto, de motivos principais para se manifestar, é radicalmente contrária ao conceito de manifestação desde a sua modalidade moderna, iniciada em Inglaterra em meados do século XVIII, até finais do século XX, centrado numa organização,

\footnotetext{
Sem a representação e a pressão da multidão na rua, as petições perdem peso político, sendo normalmente rejeitadas para discussão pelos parlamentos, caso do português. Os políticos só reagem a movimentos sociais se e como eles são representados pelas mídias (KOOPMANS, 2004).
} 
com uma elite, palavras-de-ordem previamente decididas, bandeirolas preparadas pela organização, e, amiúde, um corpo de ordem regulador da manifestação e da sua relação com os observadores na rua e com forças policiais. De um objetivo central (acabar com o tráfico de escravos, derrubar o governo, etc.) passou-se para uma concentração de diferentes prioridades e a expressão da individualidade no seio do coletivo, o que aumenta a sua capacidade mobilizadora, mas diminui a sua capacidade de mudança. Jacques Rancière chamou a atenção para este fenômeno: as manifestações políticas contemporâneas,

(...) que antes eram grandes cortejos de partidos e de sindicatos, transformaram-se em espécies de performances coletivas, mas com uma noção de colectivo em que cada um transforma a sua performance individual. Fico encantado com o fato de, nas manifestações actuais, cada pessoa chegar com os seus figurinos, as suas palavras de ordem, os seus desenhos ${ }^{8}$.

Esta diversidade resulta da organização lassa ou inexistente, que estimula um maior número de indivíduos a juntar-se a uma iniciativa que é ou lhes parece de pessoas como eles; resulta da livre expressão nas redes sociais eletrônicas, permitindo a amplitude de pontos de vista; do crescente empoderamento do indivíduo na sociedade democrática, favorecendo uma autonomia de pensamento, discurso e ação; e, finalmente, ou em consequência dos elementos anteriores, da capacidade dos novos meios de protesto permitirem a expressão pública do "ponto de viragem" na opinião pública, soltando a "maioria silenciosa" da "espiral do silêncio" (GLADWELL, 2000; BAUDRILLARD, 1982; NOELLENEUMANN, 1975) $)^{9}$. Ao contrário das manifestações disciplinadas no âmbito do modelo dos séculos passados, que decorrem muitas vezes de um processo político ou social que já se vinha expondo no espaço público (lutas sindicais, oposição a instâncias do poder político, etc.), as novas manifestações do final século XX e do século XXI são em geral "inesperadas" por terem origem fora das instituições estabelecidas (partidos parlamentares, sindicatos, etc.), por resultarem da conversa social nas redes eletrônicas, longe das mídias "tradicionais", por

\footnotetext{
Entrevista a Atual/Expresso, Lisboa, 13.06.2014.

9 O conceito de "ponto de viragem" ("Tipping Point", no original em inglês) foi exposto por Malcolm Gladwell como "aquele momento dramático numa epidemia [social] quando tudo pode mudar de repente" (GLADWELL, 2000, p. 9). Dentro da tradição anglo-americana já referida, Gladwell não aplica nesta obra o conceito a movimentos sociais de litígio com expressão multitudinária no espaço público.
} 
reunirem inúmeras subjetividades e, porque, em consequência, trazem à luz da sociedade o que antes era "silencioso". É por isso que podemos saber que, no movimento brasileiro, acordou o gigante, mas podemos perguntar-nos que gigante acordou (CARDOSO; DI FÁTIMA, 2013). Defendemos a tese que a expressão multitudinária é precisamente a via primordial, para não dizer a única, em que pode desembocar este novo tipo de protesto com origem em estruturas informais, diríamos mesmo que, amiúde, em antiestruturas informais, e mobilizando indivíduos empoderados. A multitude atinge um ponto de viragem: a multidão.

Tal como no caso egípcio, a comunicação eletrônica revelou três capacidades importantes: a rapidez da ligação, mesmo que virtual, entre um número enorme de indivíduos, e a consequente possibilidade de rapidez de ação; ${ }^{10}$ a capacitação de revelar aos indivíduos que não estavam isolados na sua opinião, cólera, etc., isto é, dando-lhe uma consciência de número; a capacidade acrescida de contrariar versões dos acontecimentos opostas às de mídias tradicionais, nomeadamente através da criação de mídias alternativas, como a Ninja. Todavia, como tentaremos mostrar adiante, subsiste a hipótese de caber às mídias "tradicionais" uma mais ampla "legitimação social" dos movimentos e suas iniciativas.

Cabe aqui referir como os grupos mais estruturados ideologicamente, caso dos movimentos anarquistas envolvidos nas manifestações no Brasil, embora seduzindo uma parte da população não-radical para os protestos, são incapazes ou não pretendem utilizar a força da multidão para desenvolver uma "norma emergente", isto é, passar à sua institucionalização e agir no âmbito do processo político burocrático estabelecido no regime democrático, como também se verifica nos Estados Unidos. Ao recorrerem por vezes à violência, alienam apoio popular e das mídias e a sua falta de interesse em passar do ponto de viragem à viragem efetiva manifesta-se na incapacidade de avaliação tática, como se verificou durante o Campeonato Mundial de Futebol em 2014. A oposição generalizada dos brasileiros, expressa em sondagens, aos custos da organização da prova e ao "padrão FIFA" - padrão de qualidade usado em estádios mas não em serviços públicos primários -,

\footnotetext{
${ }^{10}$ A aceleração da ação coletiva, porém, deverá ser estudada em confronto com casos do passado. Muitos séculos antes do prodigioso mundo atual da mass self communication (CASTELLS, 2009) as ações coletivas poderiam resultar num movimento multitudinário extenso logo após a sua ignição, bastando o passa-palavra. As revoluções simultâneas ou consecutivas na Europa no ano de 1848 são um exemplo colhido na era inicial da comunicação através de jornais, não ainda de massas. Uma vez mais, as condições sociais serão determinantes para uma causa ganhar tração.
} 
não significava a sua oposição ao futebol. Deste modo, as grandes manifestações anteriores à Copa desapareceram durante o evento; os protestos em Junho de 2014 reuniram apenas os mais militantes, alienando a potência mobilizadora das reivindicações e queixas ${ }^{11}$.

O segundo aspecto que pretendemos singularizar das manifestações no Brasil é o da relação mútua entre os manifestantes e as mídias "tradicionais". Num primeiro momento, as mídias sobrevalorizaram os episódios de violência, subvalorizaram a opinião maioritária expressa pelas multidões e chegaram mesmo a escarnecer dos protestos. A Rede Globo de televisão, a mais importante mídia "tradicional" do Brasil, destacou-se - ou foi destacada pelos manifestantes - neste processo de avaliação errada. Entretanto, os manifestantes, tal como na Tunísia, Egito ou Estados Unidos, utilizaram as redes eletrônicas para divulgar a repressão policial, a dimensão dos protestos e, também, episódios de repulsa ou mesmo de violência de manifestantes contra as mídias "tradicionais" 12 .

O "padrão Globo" de cobertura das manifestações nessa primeira fase foi, porém, muito semelhante ao que se verifica em inúmeros países democráticos ${ }^{13}$. Os "valores-notícia" geralmente vigentes nas mídias dos países de capitalismo democrático preferem reportar o processo político institucional. Quanto às iniciativas multitudinárias de litígio, valorizam os episódios de violência, como sucedeu no Brasil na primeira fase dos protestos. Por natureza, a multidão pretende a visibilidade pública, mas nem assim acede à "agenda" midiática com a mesma facilidade que qualquer declaração de um dirigente das instâncias do poder político. O acesso difícil às mídias é uma das razões para a busca de novos meios imaginativos, por vezes espetaculares, de exibição da multidão no espaço público, para que, pela novidade, consigam atrair as mídias "tradicionais", nomeadamente a televisão, como está demonstrado para o caso belga WOUTERS (2013) ${ }^{14}$. A nosso ver, as alterações a nível da performance pública da multidão resultam em boa medida da capacidade inventiva de indivíduos ou pequenos grupos, mas não alteram no fundamental o padrão histórico do repertório da ação

\footnotetext{
${ }^{11}$ Este artigo foi escrito antes e durante os movimentos políticos de 2016 no Brasil, não podendo ainda ser objeto de análise.

${ }^{12}$ São inúmeros os documentos disponíveis na Internet a este respeito. Uma análise disponível, por exemplo em SOLHA (2013).

${ }^{13}$ Para o caso norte-americano, ver GITLIN (2012), para o caso francês, ver FILLIEULE; TARTAKOWSKY (2008, p. 129-161), para o caso da televisão belga ver WOUTERS (2013), para o caso espanhol ver FOMINAYA (2013) e CASTELLS (2012, p. 110-155).

${ }_{14}$ Para o caso da televisão portuguesa, ver TORRES (2013a).
} 
coletiva desenvolvido entre os séculos XVIII e XX (TILLY; WOOD, 2009, p. 3-5).

É importante para o nosso argumento assinalar que as mídias "tradicionais" brasileiras inverteram o tom da sua informação sobre os protestos numa segunda fase, não só face à divulgação de imagens alternativas nas redes eletrônicas e aos atos de desprezo e violência sobre os seus repórteres e equipamentos, mas também porque, a nosso ver, a expressão numérica das multidões e da opinião pública, subitamente transformada em "maioria ruidosa" e em "espiral de agitação e inquietação", colocava essas mídias numa posição minoritária, alienando a sua própria audiência ${ }^{15}$. Uma mídia "tradicional", como são os grandes operadores de televisão, atribui-se a si mesmo uma representação, mesmo que difusa, da maioria ou da totalidade da população; ao informar num tom que subitamente se tornou desajustado da realidade ou pelo menos dos sentimentos político-sociais para a maioria dos brasileiros, essas mídias corriam o risco de se assumirem visivelmente como a expressão da minoria, no caso do poder político em geral, e, neste caso, de parecerem estar contra a maioria, que conta para eles, em primeiro lugar, como audiência. Podemos concluir que as mídias "tradicionais", ao alterarem o tom da informação sobre os protestos, procuraram sintonizar-se com o sentimento da maioria da população no momento e, portanto, no seu próprio interesse. Arriscamos dizer que esta mudança é irreversível. A multidão efêmera, ponto de viragem, expressão forte, se bem que informal, da opinião pública, poderá ter mudado a subjetividade de grande parte da população relativamente a formas de se fazer política e arrastou consigo as próprias mídias "tradicionais". Não foi por acaso que a rede Globo mudou a exibição das multidões, descendo à terra: na primeira fase, dominou a cobertura a partir de helicóptero; na segunda fase, prevaleceu a cobertura na rua.

Como nota final, vale a pena referir que também as autoridades policiais mudaram o seu comportamento, de violência indiscriminada numa primeira fase, para violência discriminada ou seletiva numa segunda fase. Por força da exibição midiática da violência policial e das emoções que ela proporciona - como sucedeu no caso norte-americano, como vimos - as autoridades viram-se forçadas a abandonar táticas típicas de democracias menos desenvolvidas e a adotar um "padrão

\footnotetext{
${ }^{15}$ As sondagens promovidas pelo Pew Research Center de 2010 a 2014 indicam claramente a evolução que atinge o ponto de viragem em 2014: <http://www.pewglobal.org/2014/06/03/ brazilian-discontent-ahead-of-world-cup/>. Consultado em 01.07.2014.
} 
de violência flexível", recorrendo, aliás, como veio a ser noticiado na altura do Mundial de Futebol, a polícias com mais experiência em lidar com a multidão em democracia. A polícia portuguesa já seguira esse caminho quando da Euro 2004 em Portugal, beneficiando da experiência da polícia britânica, a que mais estudou e desenvolveu comportamentos adequados à multidão da era da televisão.

\section{O caso português}

Portugal é um caso diferente dos anteriores. Não conhecemos nenhum outro país onde as manifestações de litígio e oposição aos poderes instituídos tenham uma tão grande expressão nas mídias "tradicionais", não só os canais informativos de televisão, como os próprios canais generalistas. A cobertura prévia, ao vivo e posterior a alguns eventos multitudinários, é enorme, podendo atingir muitas horas. Aconteceu com as manifestações da "Geração à Rasca" em 2011 e do movimento "Que se Lixe a Troika" em 2012, bem como com manifestações da central sindical CGTP em diversas ocasiões e uma manifestação de polícias contra o governo em 2014. Os canais de informação SIC Notícias, TVI 24, RTP Informação e a partir de 2013 CMTV fizeram transmissões ao vivo que, em diversos casos, se prolongaram por várias horas. Os canais generalistas, SIC, RTP1 e TVI, não só dedicaram grande parte dos seus noticiários a todas ou quase todas estas manifestações, como fizeram transmissões ao vivo, quer os noticiários coincidissem com os eventos, quer para dar conta dos preparativos ou das reações posteriores. O peso destes eventos nos dias ou no dia anterior e no dia seguinte é igualmente grande nos noticiários ${ }^{16}$. Os repórteres não só acompanham o desfile mas, com a colaboração das organizações, gravam ao vivo reportagens empáticas com manifestantes quando entram nos ônibus que os transportam ao local de concentração, dentro dos ônibus, na preparação de bandeirolas, colagem de cartazes apelando à participação, em piqueniques, etc. Outra diferença notável da cobertura destes eventos na televisão portuguesa é a presença dos repórteres no seio da multidão em desfile ou em concentração, tendo acontecido mesmo, sem qualquer crítica pública, uma jornalista de braço dado com um manifestante. Este estar dentro da multidão tem importantes consequências para o dispositivo audiovisual e, portanto,

\footnotetext{
${ }^{16}$ Sobre duas grandes manifestações de professores contra o Governo em 2008, TORRES (2013a,
} p. 281-295). 
para o discurso das notícias. O espectador é vicariamente colocado, também ele, junto dos manifestantes, no seu lugar, no seu movimento. Vale a pena referir que habitualmente as reportagens são feitas a partir de fora, mostrando a multidão como um corpo ao qual os repórteres, as mídias e os espectadores são estranhos. Junto dos manifestantes, os repórteres podem ainda dar conta aos espectadores dos pensamentos e emoções de manifestantes individuais, assim destacados em simultâneo do coletivo e, retoricamente, representantes desses coletivos. Ao ouvirem esses indivíduos, por vezes escolhidos pela sua representação espetacular (máscaras, adereços, etc.), os repórteres também transmitem motivações várias, por vezes bem diferentes entre si, como vimos no caso das manifestações no Brasil.

A cobertura de ações multitudinárias na televisão e nas mídias portuguesas não se limita, porém, às manifestações que se preveem grandes (e para cuja grandeza a própria cobertura midiática contribui). Pequenos eventos locais, de dezenas de pessoas em litígio com o poder (contra o encerramento de uma escola, tribunal, centro de saúde, etc.) são igualmente alvo de cobertura televisiva, o que não sucede nas mídias de âmbito nacional de outros países.

Qual a explicação para esta abertura total ou quase total das mídias portuguesas às manifestações multitudinárias? Avançamos com três hipóteses.

Consideramos que o processo revolucionário que Portugal viveu em 1974-76 determina uma atitude diferente, não só dos jornalistas, mas também da autoridade policial e da população em geral, perante meios de ação política exterior ao processo institucional-burocrático dos regimes democráticos. Os quarenta anos passados não são suficientes para apagar um fazer política popular e a "inversão parcial das hierarquias sociais", com origem nesse período, diferente do que ocorre nas democracias antigas ou que não passaram por processos revolucionários (FISHMAN, 2011, p. 233). Esta realidade social poderá ser mais importante do que a sempre referida, mas não comprovada, inclinação de uma maioria dos jornalistas para a esquerda política ${ }^{17}$. É também singular que a polícia portuguesa tenha adotado há cerca

\footnotetext{
${ }^{17}$ Num inquérito a que responderam 515 jornalistas portugueses, identificaram-se com algum partido político $27,8 \%$ e $70,7 \%$ não se identificaram. Numa escala de 1 a 10 , em que 0 representava a esquerda e 10 a direita, numa questão a que responderam 484 jornalistas, a média foi de 4,0, o que indica uma tendência para uma neutralidade ligeiramente inclinada para a esquerda, insuficiente, pois, como explicação, ou única explicação, para o fenômeno que aqui abordamos. Esta informação foi gentilmente fornecida ao autor por Adelino Gomes, em email de 29.06.2014.
} 
de vinte anos uma nova atitude face às manifestações de litígio. Essa mudança detecta-se quando se dá o boom das rádios privadas nos anos 80 e, depois, com a abertura das televisões privadas em 1992-93. Se antes a repressão era sem consequências na opinião pública, a partir dos casos extremos da manifestação de polícias reprimida pelas polícias, em 1989, ao vivo nas rádios e em diferido na então única televisão, a RTP, e do bloqueio da Ponte 25 de Abril, em 1994, este ao vivo nos vários canais, a polícia teve de adaptar-se - tal como os manifestantes - à não-violência e à força das imagens televisivas ${ }^{18}$. Não só passou a haver uma coordenação prévia cuidada com as organização dos protestos, como toda a ação policial foi produzida de modo a não atrair opiniões negativas sobre o seu comportamento. Os exemplos mais notáveis desta estratégia de ação - que é também uma estratégia de comunicação ocorreram em duas manifestações em frente do parlamento, símbolo do poder, que compete à polícia defender com firmeza, ambas televisionadas ao vivo por diversos canais ${ }^{19}$. Na primeira, em 15 de Setembro de 2012, a polícia permitiu que a sua barreira fosse alvo de agressões por bastante tempo, só agindo depois de o país ver a ação violenta de manifestantes durante um longo período. Quando agiu, com os meios repressivos habituais mas raramente usados em Portugal em eventos do tipo, o ônus da violência já se encontrava do lado dos manifestantes agressores. Os protestos sobre atos violentos da polícia foram diminutos, em especial nas redes eletrônicas, e sem expressão nas mídias "tradicionais". No segundo caso, uma manifestação de polícias em 21 de Novembro de 2013 terminando também no parlamento, a polícia de serviço limitou-se a manter a barreira firme, impedindo que a pressão dos manifestantes a rompesse. Uma vez mais, o ônus da ação para lá dos limites dos termos habituais das manifestações em democracia ficou para os polícias manifestantes. Em ambos os casos, a autoridade policial do Estado ganhou a batalha midiática.

Parece-nos igualmente de grande relevância o comportamento comunitário dos portugueses, em contraponto com o comportamento em

\footnotetext{
${ }^{18}$ SIC e TVI foram "previamente informadas" do bloqueio da Ponte, enquanto na RTP só uma jornalista "alinhada com o PCP" tinha conhecimento, cabendo-lhe realizar as primeiras notícias sobre o evento. "Para os responsáveis pela organização do bloqueio, o sucesso da operação só poderia ser conseguido se as novas televisões [SIC e TVI] fizessem a transmissão directa do que se iria passar". (LIMA, 2004, p. 305-20).

${ }^{19}$ Dada a marcação do termo destas manifestações num ponto central do poder, os canais preparam cuidadosamente suas transmissões ao vivo, com câmeras móveis e fixas, montagem de torres para elevar as câmaras, por vezes recorrendo a carro de exteriores para realização das emissões a partir do local.
} 
sociedade. O binômio comunidade/sociedade, que Ferdinand Tönnies (1979) considerou não só diacrônica como sincronicamente, é parte de cada indivíduo: cada um é ao mesmo tempo membro da sociedade, entidade abstrata que lhe providencia liberdade, autonomia, mas também solidão, e membro da ou de comunidades, entidades concretas, formadas por gente de carne e osso que lhe fornecem sentimento de pertença, companhia e sociabilidade. Portugal, país com uma unidade geográfica, linguística, política e social antiga, e com um desenvolvimento atrasado na valorização dos benefícios da sociedade, "cai" facilmente no comportamento comunitário, quer em situações de grande comoção positiva ou negativa (evento desportivo, luto nacional, etc.), quer noutras ocasiões de menor ou muito menor relevância nacional, mas que motivam uma cobertura extensiva e que chegam a tornar-se quase monopolistas dos noticiários. Seja qual for o tipo de acontecimento que entra e domina a agenda durante alguns dias, as mídias comportam-se não, como seria de esperar, na esfera da sociedade, mas de uma comunidade inteiramente absorvida por um único evento. É mais um motivo para que os eventos multitudinários adquiram um caráter de quase-monopólio na agenda informativa.

Finalmente, há que considerar a própria dinâmica concorrencial das mídias, em especial da TV. Sendo Portugal um país de dimensão pequena, dispõe de três canais nacionais com audiências razoavelmente semelhantes (RTP1, SIC, TVI), a que se deve somar um número de canais de informação por cabo que impressiona pela quantidade e êxito num mercado reduzido: RTP3, SIC Notícias, TVI 24, CMTV, Econômico TV e ainda o regional, mas de acesso nacional, Porto Canal. A esses, somam-se não só os canais de informação internacionais disponíveis por cabo, como os canais de informação desportiva, com audiência substantiva. A concorrência, no jornalismo, tem uma dinâmica paradoxal: motiva a busca pela diferenciação ao mesmo tempo em que acentua a imitação nos temas da agenda. Esta imitação é particularmente acentuada nos canais portugueses, com alinhamentos nos noticiários por vezes quase idênticos. A coincidência na agenda nota-se com mais força no caso de grandes eventos, como o são as previsíveis manifestações de impacto, na capital ou em várias cidades em simultâneo. Esta característica da televisão portuguesa não é de modo nenhum, a nosso ver, um particularismo sem consequências. Pelo contrário, a forte concorrência dos vários operadores, num mercado exíguo, mas bastante dinâmico e competitivo, tem mostrado estar à frente de outros mercados em tendências que cedo desenvolveu. Deste modo, não seria de estranhar 
que mercados televisivos de outros países evoluam no mesmo sentido. A rápida sintonização das mídias brasileiras com a sociedade em 2013 é um sinal.

\section{O novo e o velho: discussão de alguns temas}

A ocorrência em simultâneo do desenvolvimento dos "novos movimentos sociais", da Internet e outros meios técnicos comunicacionais e da decadência de meios jornalísticos impressos motivou observações e análises que, a nosso ver, sobrevalorizam os elementos de mudança e esquecem realidades do passado. Em primeiro lugar, as redes sociais eletrônicas foram confundidas com redes sociais tout court, o que levou a visões em boa medida milenaristas acerca das suas capacidades de transformação radical da sociedade (HARDT; NEGRI, 2005; CASTELLS, 2013). Na verdade, todas as sociedades, das mais simples às mais complexas, são um conjunto de redes sociais, mais ou menos difusas, maiores ou menores. $\mathrm{O}$ estudo de movimentos passados que desembocaram em eventos multitudinários revela a existência de redes sociais com a eficácia possível de acordo com os meios técnicos disponíveis. Avançamos com o sobrevoo de dois exemplos portugueses, incidindo a análise do segundo igualmente na relação com as mídias.

Em 1637, rebenta em Évora, Portugal, um movimento social contra medidas tributárias injustas, no âmbito da dominação espanhola, já então numa fase opressiva e repressiva ${ }^{20}$. O movimento popular clandestino esteve sempre em contato com a elite da aristocracia e do clero portugueses, cuja situação se tornava especialmente difícil pelo fato de envolver o candidato óbvio à coroa se Portugal recuperasse a independência. O movimento social, quer na situação multitudinária, quer nos eventos que se lhe seguiram, esteve sempre ativo e utilizou declarações anônimas para manter a população informada e a oposição acesa (Torres, 2013b). A revolta em Évora motivou revoltas em outros locais no Centro e Sul do país, o que implica igualmente uma rede de contatos, seja por comunicação oral, seja pelo meio técnico disponível, o papel. O caráter pré-moderno da revolta não diminuiu o seu impacto - foi um, se não o rastilho da Restauração de 1640. O seu lugar na História deveu-se ao evento efêmero, multitudinário, que marcou contemporâneos e cronistas, influenciando o devir histórico.

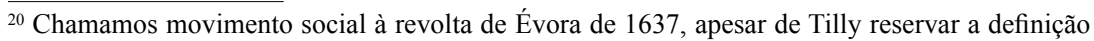
para os movimentos surgidos no final do século XVIII e de formato estável no século seguinte (TILLY; TARROW, 2007).
} 
Em 1903, um pequeno motim numa fábrica têxtil no Porto desencadeou um enorme movimento social na segunda maior cidade portuguesa e nos concelhos limítrofes. A greve naquela fábrica originou uma greve geral na cidade, de diversas classes profissionais. Foi a maior greve a que o país assistiu até então (abrangendo entre 35 e 45 mil trabalhadores, mais de cem mil se incluídos os familiares) e foi uma das mais longas, prolongando-se por mais de três meses. O estudo das notícias e comentários na imprensa burguesa do Porto permite retirar duas conclusões pertinentes para este artigo.

Primeiro, o movimento operário, anarquista, funcionava em rede com uma enorme eficácia, que apanhou as autoridades e os industriais totalmente desprevenidos. O movimento recorria a reuniões constantes, legais, mas principalmente clandestinas, reunindo ora centenas ora milhares de trabalhadores. Utilizava também panfletos, comunicados e declarações, reproduzidos na imprensa. As decisões eram tomadas nas assembleias, como vemos acontecer em movimentos anarquistas ou de inspiração anarquista atualmente, mas com uma agenda focada nos interesses dos grevistas e um tempo de decisão quase imediato.

$\mathrm{O}$ segundo aspecto traz-nos à relação mútua entre as mídias "tradicionais" e o movimento social. Nos primeiros dias, as notícias ou comentários sobre a greve na imprensa burguesa - cujo padrão de objetividade factual era enorme - são desfavoráveis ao operariado, nomeadamente porque, como era uso na época, em alguns casos se recorreu à violência contra a propriedade dos industriais. Todavia, a atitude da imprensa mudou radicalmente a partir dum evento concreto: os operários, enquadrados pelos anarquistas, realizaram manifestações pacíficas no coração burguês do Porto. Numa primeira fase, a autoridade armada brutalizou homens, mulheres e crianças. Embora não esteja ainda comprovado, é provável que o envio das mulheres e crianças das famílias grevistas pedindo esmola contra a fome tenha sido propositado para conquistar as mídias e a opinião pública através da vivência no centro da cidade, da exibição de emoções e das notícias ${ }^{21}$. A atenção dos jornais à progressão do movimento aumentou significativamente, sendo manchete por várias vezes. Os comentários condenaram a ação policial e, ora apoiaram os grevistas contra a, assim vista então, obstinação dos industriais, ora defenderam a conciliação de classes. Na ausência de estruturas de regulação entre o capital e o trabalho, o representante do

${ }^{21}$ Esta tática de "emocionalização" da opinião pública já teria sido usada antes em Espanha em eventos enquadrados por anarquistas. 
governo no Porto passou a intervir como mediador. A polícia mudou de atitude e, quando não, continuou a ser criticada pelas mídias. $\mathrm{O}$ auge da relação entre a imprensa e os grevistas surgiu quando os jornalistas decidiram fazer um pedido pela cidade para combater a dificuldade das famílias operárias. Os jornalistas pediram aos grevistas para não se manifestarem com eles, mas estes se juntaram a eles sem oposição, formando uma multidão única nas ruas da cidade (TORRES, 2013c; 2015).

Podemos concluir que a necessidade de interação dos grevistas com as mídias "tradicionais" os levou à adoção de novas táticas: a nãoviolência, a vitimização social e da repressão policial, a exploração das emoções de comiseração do público não operário (originando descrições pungentes na imprensa), a ocupação multitudinária do espaço público central, o recurso a táticas espetaculares, como a utilização de mulheres e crianças, a passagem de informações aos jornais (incluindo sobre as inúmeras reuniões clandestinas realizadas de noite ou madrugada). É significativo que o movimento operário tenha prescindido dos seus próprios meios de comunicação legais, a imprensa operária (praticamente inútil como fonte sobre os eventos), que serviria também para a afirmação da rede social, e preferisse agir de modo a conquistar a mais ampla opinião pública através da imprensa burguesa, "tradicional", à época vibrante e ideologicamente diversa. Mesmo o jornal mais conservador, com uma linguagem fortemente antigreve, acabou por juntar-se aos colegas no requerimento a favor dos operários. Deste modo, este movimento social de 1903, liderado pelo grupo social mais pobre, os operários têxteis, numa cidade secundária de um país periférico, apresenta praticamente todas as características dos "novos" movimentos sociais, quer quanto à relação com as mídias, quer quanto à ação em rede difusa, sem chefes, ao processo decisório e ainda ao apelo à solidariedade nacional e internacional. Os grevistas venceram em quase todas as suas reivindicações, mas o movimento anarquista e operário no Porto não voltou a ter uma expressão semelhante ${ }^{22}$.

Um segundo tema sobre o velho e o novo é o do caráter internacional de certos movimentos sociais na era da globalização, sublinhado na literatura especializada (por exemplo, SOMMIER, 2003). Ele ocorre não só com organizações de natureza internacional, como a Greenpeace,

\footnotetext{
${ }^{22}$ Ao contrário de outros movimentos sociais com forte expressão multitudinária, esta greve geral desapareceu da memória coletiva, dada a falta de propensão dos anarquistas para institucionalizarem a sua própria memória e do desinteresse dos socialistas. Além dos trabalhos referidos, não existem monografias sobre o evento.
} 
mas também com certos movimentos concretos, caso das manifestações "Povos unidos contra a Troika" em 18 países na Europa em 1 으 de Junho de 2013. Nestes últimos casos, verifica-se que são iniciativas multitudinárias sem aparente continuação em movimentos perenes com significado relevante em cada um dos países em que ocorrem ou no seu conjunto.

Pode dizer-se que esta internacionalização é um fenômeno marcante de certos movimentos sociais. O caso mais notável é, a nosso ver, o dos protestos em Seattle por ocasião de um encontro da Organização Mundial do Comércio em 1999. Preparados durante cerca de dois anos, os protestos foram inesperados para as autoridades norte-americanas e da OMC. O protesto, reunindo manifestantes de inúmeros países, recorreu à violência, interrompeu a reunião, obrigou ao recorreu obrigatório e incluiu diversas ações do repertório espetacular com impacto nas mídias. O formato deste evento multitudinário foi depois usado por ocasião de outras cimeiras internacionais. As mídias internacionais permitem um impacto e uma influência aos movimentos, nomeadamente nacionais. Foi o caso da Primavera Árabe: movimentos como o tunisino e o egípcio foram nacionais, se bem que interligados, mas a comunicação, nomeadamente dos canais internacionais e televisão, como a BBC World, a CNN International, a France Internacional e a Al Jazeera, teve um papel preponderante na internacionalização dos eventos nacionais.

Pretendemos salientar, porém, o limite das ações internacionais, aliás, referido na literatura sobre os movimentos sociais, dada a perene estruturação nacional dos países, dos seus povos e de suas principais mídias. $\mathrm{O}$ internacionalismo é difícil de manter nas organizações, nas opiniões públicas e na captação da atenção midiática.

Vale a pena, entretanto, regressar à história para relativizar a novidade das ações simultâneas internacionais. É certo que a simultaneidade é hoje muito fácil para os movimentos e atraente para as televisões, dado que o caráter da linguagem televisiva passa exatamente pela simultaneidade, ao vivo, entre o tempo do emissor e o do receptor. Mas a simultaneidade não é nova. Religiões como o cristianismo e o islamismo codificaram há milênios os eventos simultâneos em toda a sua área de implantação, com a chamada dos fiéis em simultâneo ou à mesma hora. O movimento operário internacional retomou esta característica ao instituir o $1^{\mathrm{O}}$ de Maio em todo o mundo. O caráter de simultaneidade das multidões do Dia dos Trabalhadores foi realçado desde a criação da efeméride no final do século XIX (TORRES, 2013a, p. 269). Deve notar-se que a perenidade do $1^{\mathrm{O}}$ de Maio, entretanto institucionalizado 
na maior parte dos países democráticos, se deve não só à continuidade do movimento sindical até ao nosso tempo, mas também ao crescente caráter nacional das manifestações. Convém ainda recordar que, antes dos movimentos sociais litigiosos de caráter internacional, outro tipo de atividade recorreu aos eventos multitudinários internacionais e simultâneos: a indústria da música popular, exemplificada nos concertos Live Aid de 1985 e Live 8 em 2005. Dado que a simultaneidade da multidão num só lugar é mais favorável ao discurso midiático e da própria multidão do que a sua dispersão por diferentes locais do mundo, verifica-se que os eventos globais de maior impacto são precisamente os que concentram manifestantes de todo o mundo num só lugar, como mostrou o exemplo pioneiro de Seattle. Nesse sentido, os eventos internacionais dos movimentos sociais de maior êxito e perenidade na memória coletiva são os que seguem o modelo dos grandes eventos internacionais espetaculares, do desporto e da música, como os Jogos Olímpicos (criados como evento "global" pelos antigos gregos), ou os Oscars norte-americanos, que a hegemonia da cultura popular norteamericana no mundo e o impacto da televisão mundial transformaram num evento global.

\section{Conclusão}

Para terminar, gostaríamos de debater o tema das "novas" e das "velhas" ou "tradicionais" mídias, como pano de fundo para a midiatização dos eventos multitudinários contemporâneos. O desenvolvimento exponencial da comunicação eletrônica nas últimas décadas motivou não só teorias utópicas sobre as capacidades de alteração social a "partir da técnica", como, a um nível mais básico, originou confusão entre, por exemplo, a Internet - canal de comunicação, o meio físico por onde passa a mensagem - e a mensagem e seus intervenientes. Assim, a Internet é comumente identificada como uma mídia, quando a Internet está para a comunicação como o papel ou as ondas hertzianas. Sendo obrigatório sublinhar a importância extraordinária da Internet e das outras técnicas de comunicação eletrônica para o empoderamento dos indivíduos, para o reforço de redes de contatos, de informação e de ideias, é porventura chegado o momento de se estudar os limites sociais da comunicação eletrônica. A nosso ver, a comunicação eletrônica potencia a comunicação e a informação, mas não necessariamente a mobilização e a ação, que já ocorriam com os meios anteriores, mais ou muito mais limitados. Terá de se encontrar explicações sociais e não 
(apenas) técnicas para a mobilização. As chamadas redes sociais, como o Facebook ou o Twitter, são redes sociais eletrônicas, redes sociais virtuais, ou pelo menos com uma grande dimensão virtual, insuficiente para transferir para a ação física, fora dessa virtualidade. A mobilização de "likes" não corresponde à mobilização para a ação. A amargura perante esse desfasamento fica bem expressa nas declarações de uma ativista e atriz na televisão portuguesa, Ana Sofia Martins:

Vejo uma inércia muito grande. As pessoas protestam nas redes sociais, mas não fazem mais do que isso. Somos todos revolucionários do Facebook. Queixamo-nos todos que o [primeiroministro] Passos Coelho governa mal, mas depois não saímos do computador. [...] Se calhar, se existissem computadores e redes sociais, o 25 de Abril não teria acontecido. ${ }^{23}$

A nosso ver, são as condições sócio-políticas que explicam o êxito ou fracasso da mobilização, eletrônica ou não, de um evento multitudinário. Sublinhemos este aspecto com um exemplo notável: o movimento português "Que Se Lixe a Troika", estruturado a partir das redes sociais eletrônicas, teve resultados totalmente contrários na convocação de manifestações: em 2012, alcançou um êxito enorme, com uma multidão de muitas dezenas de milhar de pessoas em Lisboa; no ano seguinte, não conseguiu reunir mais de uma centena e meia de pessoas.

Em qualquer caso, a mobilização possível pelas redes sociais - que, por intuição, podemos dizer não ultrapassar muito a que já era possível, em termos percentuais, antes da comunicação eletrônica - necessita quase sempre da concretização no espaço público em eventos multitudinários. Quer dizer, a multitude de Hardt e Negri ganha eficácia quando se transforma em multidão ${ }^{24}$. A "comunidade imaginada" (ANDERSON, 1991) poderá alargar-se pelas redes eletrônicas com a interação e a self mass communication, mas é ainda uma comunidade imaginada. Mas não é ainda uma forma social, em sentido simmeliano (SIMMEL, 1971), como a multidão é há milênios. Na rua, a comunidade vê-se, ou julga ver-se e ser vista. Se outros meios, como as petições, ganharam

\footnotetext{
${ }^{23}$ Entrevista no jornal $i, 31.03 .2014$. As redes sociais potenciam a influência social daqueles com quem se contata: segundo um estudo, "vai muito além do que se pensava" (Público, 04.03.2014). O impacto dessa influência na opinião é há muito estudado na sociologia (KATZ; LAZERSFELD, 1955), faltando conhecer o seu impacto na mobilização. O uso das redes como simples "desabafo" é intuído até pelos políticos: Marques Mendes, ex-presidente do PSD, sugeriu “"Desabafem nas redes sociais", não nas urnas" (Público, 19.05.2014).

${ }^{24}$ Poderá não ser esta a opinião de Hardt, que, num texto posterior ao livro com Negri, exprimiu a sua aversão pela multidão (SCHNAPP; TIEWS, 2006, p. 35-40).
} 
tremendamente com a comunicação eletrônica - por não necessitarem de mais do que essa mesma comunicação eletrônica -, a maioria dos movimentos exemplares precisa de desembocar na multidão, para concretizar diversas funções: a exibição do protesto, a sua dimensão, a ocupação do espaço público, a expressão dum meio "contrademocrático" perante um bloqueio subjetivo ou objetivo das instituições democráticas e a intenção de sinédoque, de representação dum número maior do que aquele que ocupa as ruas. Nas redes eletrônicas, o movimento não se vê; nas ruas, é "ver para crer". Ou melhor: nas redes eletrônicas, o movimento adquiriu um maior conhecimento da extensão da opinião e, portanto, da causa; ele é quantificável, pelo número de mensagens, de "gostos", de declarações de adesão. Este conhecimento é um enorme passo em frente para qualquer iniciativa em relação ao passado, quando a "espiral do silêncio" dificilmente se transformava no seu oposto. Todavia, a adesão quantificada a uma causa pelas redes eletrônicas, se tem a potência transformadora, não é ainda a própria transformação, a qual, a nosso ver, ocorre quando a multidão (a concretizar-se) mostra o movimento social à sociedade, nas ruas e nas mídias "tradicionais". A multidão é o prolongamento e a confirmação da mobilização pelas redes sociais, que apenas existe em potência. De acordo com a sua sintonia com a sociedade, a multidão representará o ponto de viragem. As mídias "tradicionais" podem ter aí um papel importante, se em sintonia com a sociedade.

Antes de concluirmos, porém, convém esclarecer o que entendemos por mídias "tradicionais". Esta expressão, ou outras semelhantes, refere-se a jornais, estações de rádio e de televisão, generalistas ou por cabo, geralmente de informação jornalística, em oposição a redes sociais e Internet. De novo, a apreciação da técnica se sobrepõe ao fundamento da comunicação. Parece-nos que uma mídia jornalística deve ser considerada, sociologicamente, como uma instituição legalmente estabelecida como empresa jornalística, com obrigações gerais e específicas no âmbito do jornalismo e que é socialmente reconhecida como uma produtora de informação de acordo com as regras do jornalismo escritas na lei e partilhadas pela sociedade. Assim, é irrelevante qual o meio técnico de produção, disseminação e recepção quando se trata de avaliar a relação de uma mídia com a opinião pública. Ela é autorizada pela burocracia do Estado democrático e é validada pelos seus consumidores, que a mantêm viva, sendo essa, em termos gerais, uma validação pela sociedade. Queremos assim dizer que, numa sociedade, existem as mídias que ela alimenta e de que se 
alimenta. A inscrição das mídias no corpo profundo da sociedade é uma realidade muitas vezes esquecida pelas análises midiáticas, por serem eles também a pele, ou uma pele que nos toca nos sentidos da audição e da vista. Daí que as metáforas das mídias como espelho da realidade e da televisão como janela para o mundo tenham feito com êxito um percurso de décadas. Se há nelas uma parte verdadeira, todas esquecem que as mídias não estão de fora da sociedade a olhá-la e a reproduzila; eles fazem parte da própria sociedade e funcionam com ela como os vasos comunicantes, para propor uma outra metáfora. As mídias recebem da sociedade o que ela produz, e não só lhe devolvem o que ela produz como criam novas realidades que a sociedade absorve. As mídias procuram o equilíbrio com o pulsar da sociedade. Não pode o vaso das mídias ter muito mais "líquido" do que o da sociedade, nem pode ter muito menos do que esse: as mídias têm de procurar o equilíbrio com o output da sociedade, pois correm o risco de estar demasiado "cheias", à frente da sociedade, ou demasiado "vazias", atrás dela. Por causa desta busca de equilíbrio constante nos vasos comunicantes com a sociedade as mídias "tradicionais" são consensualmente consideradas como suas representantes informais. Elas avançam ou recuam nas tradições e nas novidades sociais consoante sentem ou pressentem essas mudanças na sociedade, de modo a servirem e, assim, terem o favor e o consumo pelos seus públicos.

Deste modo, a maioria dos movimentos sociais sabe por instinto que precisa mais das mídias "tradicionais" do que o inverso. Contrariando ativistas que exprimiam o habitual lamento contra a cobertura das suas ações pelas mídias "tradicionais", Nuno Ramos de Almeida, um dos organizadores das manifestações "Que Se Lixe a Troika", escreveu a 22 de Outubro de 2013 no Facebook: "Os nosso inimigos não são os jornalistas". Um ativista de língua francesa acrescentou: "Não cometam o erro de vos enganarem sobre quem é o inimigo [...]. Vocês precisam da imprensa para o vosso combate". Pode acontecer que um movimento social prescinda da cobertura midiática devido às suas convicções, como o Occupy; pode acontecer que os movimentos sociais adaptem a sua comunicação e aspectos formais do repertório de ação para captar o interesse midiático; pode acontecer que as mídias tenham de se adaptar ao vaso comunicante da sociedade por se verificarem desfasadas da "maioria silenciosa", como sucedeu no Brasil; mas é uma constante da vida comum em democracia que os movimentos sociais com impacto na vida do conjunto da sociedade são os que obtêm depois uma cobertura das mídias "tradicionais", em especial da televisão, o meio mais 
adaptado para, pelas imagens e sons, mostrar o ato multitudinário, o ato audiovisual da multidão, o zênite da vida da maioria dos movimentos, o seu ponto de viragem e de encontro com a sociedade em geral através das mídias consensualmente vistas como os comunicadores informais da sociedade.

\section{Referências}

ANDERSON, Benedict. Imagined Communities. Londres: Verso, 1991.

ASWANY, A. A. O Estado do Egito. O que tornou a revolução possível. Lisboa: Quetzal, 2011.

BAUDRILLARD, Jean. À l'ombre des majorités silencieuses. Paris: Éditions Denoël/ Gonthier, 1982.

BORCH, Christian. The Politics of Crowds. Cambridge: Cambridge University Press, 2013 BOUGNOUX, Daniel. La crise de la représentation. Paris: La Découverte, 2006

CARDOSO, Gustavo; DI FÁTIMA, Branco. Movimento em Rede e Protestos no Brasil: Qual Gigante Acordou? In: Revista Eco-Pós. Rio de Janeiro, v. 16, n. 2, p. 143-176, maio/ago. 2013. Disponível em: <www.pos.eco.ufrj.br>. Acesso em: 03 jul. 2014.

CASTELLS, Manuel. Communication Power. Oxford: Oxford University Press, 2009.

. Networks of Outrage and Hope. Cambridge: Polity, 2013.

CHAMPAGNE, Patrick. Faire l'opinion. Paris: Les Éditions de Minuit, 1990.

CHIAROMONTE, Alessandro. Party-System Volatility, Regeneration and DeInstitutionalization in Western Europe (1945-2015). In: Party Politics, 2015. p. 1-13. Disponível em: < http://ppq.sagepub.com/content/early/2015/08/24/1354068815601330. full>. Acesso em: 06 Abr. 2016

COOLEY, Charles Horton. Democracy and Crowd Excitement. Social Organization, Nova York: Charles Scribner's Sons, 1909. p. 149-156.

DELLA PORTA, Donatella; DIANI, Mario. Los Movimientos Sociales. Madrid: Editorial Complutense, 2011.

ELTANTAWY, N.; WEST, J. B. Social Media in the Egyptian Revolution: Reconsidering Resource Mobilization Theory. In: International Journal of Communication, v. 5, p. 1207-1224, 2011.

FILLIEULE, Olivier; MATHIEU, Mathieu; PÉCHU, Cécile (Dir.). Dictionnaire des mouvements sociaux. Paris: Sciences Po. Les Presses, 2009.

FILLIEULE, Olivier; PÉCHU, Cécile. Lutter ensemble. Paris: L'Harmattan, 2014.

FILLIEULE, Olivier; TARTAKOWISKY, Danielle. La manifestation. Paris: Sciences Po. Les Presses, 2008.

FILLIEULE, Olivier; AGRIKOLIANSKY, Éric; SOMMIER, Isabelle (Dir.). Penser les mouvements sociaux. Paris: La Découverte, 2010.

FISHMAN, Robert M. Democratic Practice after the Revolution: The Case of Portugal and Beyond. In: Politics \& Society, v. 39, n. 2, p. 233-267, 2011. http://dx.doi. org/10.1177/0032329211405439 
FOMINAYA, Cristina Flesher. The Madrid Bombings and Popular Protest: misinformation, Counter-Information, Mobilisation and Elections after '11-M'. In: DRURY, John; STOTT Clifford (Ed.). Crowds in the 21st Century. Londres: Routledge, 2011. p. 17-35.

GHONIM, Wael. Revolution 2.0. Boston, Ms: Houghton Mifflin Harcourt, 2012.

GITLIN, Todd. The Whole World is Watching. Berkeley, CA: University of California Press, 2003.

GITLIN, Todd. Occupy Nation. Nova York: Harper Collins, 2012.

GLADWELL, Malcolm. The Tipping Point. Little: Brown, 2000.

GOODWIN, Jeff; JASPER, James M.; POLETTA, Francesca (Ed.). Passionate Politics. Chicago; Londres: Chicago University Press, 2001.

HARDT, Michael; NEGRI, Antonio. Multidão. Porto: Campo das Letras, 2005.

KATZ, Eliuh; LAZARSFELD, Paul. Personal Influence. Nova York: The Free Press, 1955.

KOOPMANS, Ruud. Movements and Media: Selection Processes and Evolutionary Dynamics in the Public Sphere. In: Theory and Society. v. 33, n. 3-4, p. 367-391, 2004.

LIMA, Fernando. O Meu Tempo com Cavaco Silva. Lisboa: Bertrand, 2004.

MATHIEU, Lilian. La démocracie protestataire. Paris: Sciences Po. Les Presses, 2011.

MCCLELLAND, J. S. The Crowd and the Mob. Londres: Unwin Hyman, 1989.

NEVEU, Érik. Médias et protestation collective. In: FILLIEULE, Olivier; AGRIKOLIANSKY Éric; SOMMIER, Isabelle (Dir.). Penser les mouvements sociaux. Paris: La Découverte, 2010. p. 245-264.

NEVEU, Érik. Sociologie des mouvements sociaux. Paris: La Découverte, 2011.

NOELLE-NEUMANN, E. The Spiral of Silence. Chicago: Chicago University Press, 1975.

NUNNS, A.; IDLE, N. Tweets from Tahrir. New York: OR Books, 2011. Disponível em: <http://books.google.pt/books?id=5umjr9H-cH8C\&printsec=frontcover\&hl=pt$\mathrm{PT} \# \mathrm{v}=$ onepage \&q\&f=false $>$. Acesso em: 02 jul. 2014.

ROSANVALLON, Pierre. La contre-démocracie. Paris: Seuil, 2006.

SCHNAPP, Jeffrey T.; TIEWS, Matthew (Ed.). Crowds. Stanford, CA: Stanford University Press, 2006.

SIMMEL, Georg. On Individuality and Social Forms. Chicago; Londres: The University of Chicago Press, 1971.

SOLÉ, Jacques. Révolutions et révolutionnaires en Europe, 1789-1918. Paris: Gallimard, 2008.

SOLHA, Hélio L. A Media e as manifestações de junho: controle e disputa. 2013. In: HAROCHE, Claudine; LOPES Myriam Bahia; DÉLOYE, Yves (Org.). Ensaios sobre a arrogância. Belo Horizonte: NEHCIT/EA UFMG, 2015. p. 72-82.

SOMMIER, Isabelle. Le renouveaux des movements contestataires à l'heure de la mondialisation. Paris: Flammarion, 2003.

TARDE, Gabriel. A Opinião e as Massas. São Paulo: Martins Fontes, 1992.

TILLY, Charles. The Politics of Collective Violence. Cambridge: Cambridge University Press, 2006. 
TILLY, Charles; WOOD, Lesley J. Social Movements: 1768-2008. Boulder, Londres: Paradigm, 2009.

TILLY, Charles; TARROW, Sidney. Contentious Politics. Oxford: Oxford University Press, 2007.

TÖNNIES, Ferdinand. Comunidad y Asociación. Barcelona: E. Península, 1979.

TORRES, Eduardo Cintra. Representações da Multidão Política na Televisão. In: FREIRE FILHO, João; BORGES, Gabriela (Eds.). Estudos de Televisão. Porto Alegre: Sulina, 2011. p. 149-180.

TORRES, Eduardo Cintra. A Multidão e a Televisão. Representações Contemporâneas da Efervescência Colectiva. Lisboa: Universidade Católica Editora. 2013a.

. Durkheim's Concealed Sociology of the Crowd. In: Durkheimian Studies, British Centre for Durkheimian Studies, University of Oxford, v. 20, n. 1 (26), p. 89-114, Winter 2014. Disponível em: <http://berghahn.publisher.ingentaconnect.com/ content/berghahn/durk/2014/00000020/00000001/art00005>. Acesso em: 06 abr. 2016.

. A Multidão Medieval e Moderna: Representações Políticas em Fernão Lopes e D. Francisco Manuel de Melo. In: SILVA, Pedro Alcântara da; SILVA, F. Carreira da (Org.). Ciências Sociais: Vocação e Profissão. Lisboa: ICS, 2013b. p. 95-116.

. Representação Ficcional da Greve Geral e da Multidão Operária no Porto em 1903. In: LOURENÇO, A. A; SANTANA, M. Helena; SIMÕES, M. João (Coord.). $O$ Século do Romance. Coimbra: Centro de Literatura Portuguesa, 2013c. p. 75-87.

. An Early Example of Media, Social Movements and Crowd Interaction: The Oporto General Strike of 1903. In: TORRES, Eduardo Cintra; MATEUS, Samuel (Ed.). From Multitude to Crowds: Collective Action and the Media. Frankfurt: Peter Lang Ed., 2015. p. 111-141.

TURNER, Ralph H.; KILLIAN, Lewis M. Collective Behavior. 3. ed. Englewood Cliffs, NJ: Prentice Hall. 1987.

VV.AA. Cidades Rebeldes. S.1: Carta Maior e Boitempo. 2013. Disponível em: < http:// ujceara.files.wordpress.com/2014/01/cidadesrebeldes-passelivreeasmanifestac3a7c3b5 esquetomaramasruasdobrasil.pdf>. Acesso em: 01 jul. 2014.

WOUTERS, Ruud. From the Street to the Screen: Characteristics of Protest Events as Determinants of Television News Coverage. In: Mobilization, v. 18, n. 1, p. 83-105, 2013. ZOLA, Émile. Germinal. Paris: Gallimard. 1978.

Recebido: 09 de março de 2016 Aprovado: 03 de junho de 2016

\footnotetext{
Autor/Author:

EDUARDO CINTRA TORRES <eduardocintratorres@gmail.com>

- Professor Auxiliar Convidado da Universidade Católica Portuguesa (UCP) e investigador do Centro de Estudos de Comunicação e Cultura (CECC). PhD, Instituto de Ciências Sociais da Universidade de Lisboa (ICS-UL). Últimas publicações: Telenovela, Indústria \& Cultura, Lda. Lisboa: Fundação Francisco Manuel dos Santos, 2015; e A Multidão e a Televisão. Representações Contemporâneas da Efervescência Colectiva. Lisboa: UCE, 2010. Áreas de interesse de investigação: Estudos de Televisão; Sociologia das Midias; Sociologia da Literatura; Sociologia dos Movimentos Sociais; Análise de Publicidade.

- Visiting Assistant Professor of the Universidade Católica Portuguesa (UCP) and researcher of the Research Centre for Communication and Culture (CECC). PhD from the Instituto de Ciências Sociais da Universidade de Lisboa (ICS-UL). Last publications: Telenovela, Indústria \& Cultura, Lda. Lisboa: Fundação Francisco Manuel dos Santos, 2015; and A Multidão e a Televisão. Representações Contemporâneas da Efervescência Colectiva. Lisboa: UCE, 2010. Areas of interest: Television Studies; Media Sociology; Literature Sociology; Social Movements Sociology; Advertising Analysis.
} 